\title{
1999 Marmara Depremi ve Güneş Tutulmasının Naive Bayes Sınıflayıcısı ile İstatistiksel Analizi
}

\author{
Seçil Karatay ${ }^{*}$, Muna O.A. Algahani ${ }^{2}$ \\ 1* Kastamonu Üniversitesi, Mühendislik ve Mimarlık Fakültesi, Elektrik Elektronik Mühendisliği Bölümü, Kastamonu, Türkiye, (ORCID: 0000-0002-1942-6728), \\ skaratay@kastamonu.edu.tr \\ ${ }^{2}$ Kastamonu Üniversitesi, Mühendislik ve Mimarlık Fakültesi, Malzeme Bilimi ve Mühendisliği Bölümü, Kastamonu, Türkiye, (ORCID: 0000-0002-9451-5376), \\ muna03060@gmail.com
}

(İlk Geliş Tarihi 7 Şubat 2021 ve Kabul Tarihi 7 Nisan 2021)

(DOI: 10.31590 /ejosat.876223)

ATIF/REFERENCE: Karatay, S. \& Algahani, M.O.A. (2021). 1999 Marmara Depremi ve Güneş Tutulmasının Naive Bayes Sınıflayıcısı ile İstatistiksel Analizi. Avrupa Bilim ve Teknoloji Dergisi, (23), 643-648.

$\ddot{O} z$

İyonosfer, atmosferin 50 ila $1000 \mathrm{~km}$ yükseklikleri arasında yer alan, güneşten gelen radyasyonla plazma durumuna iyonize olmuş, önemli bir katmanıdır. İyonosferik plazmanın en belirleyici parametresi, güneş, jeomanyetik ve sismik hareketlilikle ve güneş patlamaları, Güneş Lekelerinin Sayısı, güneş rüzgârı, jeomanyetik firtınalarla değişkenlik ve bağlaşım gösteren elektron yoğunluğudur. Elektron yoğunluğunun ölçülebilir önemli bir niceliği de, iyonosfer ve üst atmosferin yapısını araştırmak için etkili bir yol sağlayan Toplam Elektron İçeriği'dir (TEİ). TEİ, bir ışın yolu boyunca elektron yoğunluğunun çizgi integrali veya bir ışın yolu boyunca toplam elektron sayısı olarak tanımlanmaktadır. İyonosferin uzamsal-zamansal değişkenliği, ayrıca, uzamsal-zamansal yönsemeler ve Yer'in manyetik alanındaki bozulmalar, yerçekimi dalgaları ve sismik hareketliliğin üst atmosfere ve iyonosfere bağlaşımından da etkilenmektedir. Bu değişkenliklerin bazıları iyonosferde belirli bir frekans, süre ve hızda yayılan dalga benzeri salınımlar üretir. Bu çalışmada, sismik, güneş ve jeomanyetik hareketliliğe bağlı olarak iyonosferde meydana gelen bozulmaların ve iyonosferin sakin olarak nitelendirilen durumundan sapmaların tespiti için Naive Bayes Sınıflandırıcısı kullanılmıştır. Naive Bayes Sınıflandırıcısı, Türkiye üzerinde konumlandırılmış Yerküresel Konumlama Sistemi (YKS) istasyonlarından 1999 yılında meydana gelen güneş tutulması ve Marmara Depremi periyodunca kestirilen TEİ verilerine uygulanmıştır.

Anahtar Kelimeler: Naive Bayes Sinıflayıcısı, İyonosfer, TEİ, Deprem.

\section{Statistical Analysis of 1999 Marmara Earthquake and Solar Eclipse with Naive Bayes Classifier}

\begin{abstract}
The ionosphere is an important layer of the atmosphere between 50 and $1000 \mathrm{~km}$ altitudes, which isionized to the plasma state by radiation from the sun. The most determining parameter of ionospheric plasma is the electron density, which varies and correlates with solar, geomagnetic and seismic activity and solar flares, Sun Spots Number, solar wind and geomagnetic storms. An important measurable quantity of electron density is the Total Electron Content (TEC), which provides an efficient way to investigate the structure of the ionosphere and upper atmosphere. TEC is defined as the line integral of electron density along a beam path or the total number of electrons along a beam path. The spatio-temporal variability of the ionosphere is also affected by the spatial and temporal trends and disturbances in the geomagnetic field, gravitational waves and seismic activity coupled to the upper atmosphere and ionosphere. Some of these variations produce wave-like oscillations propagating in the ionosphere at a certain frequency, duration and speed. In this study, the Naive Bayes Classifier is used to detect disturbances in the ionosphere due to seismic, solar and geomagnetic activities and deviations from the quite state of the ionosphere. Naive Bayes Classifier is applied to TEC values obtained from Global Positioning System (GPS) stations during 1999 solar eclipse and the Marmara earthquake periods.
\end{abstract}

Keywords: Naive Bayes Classifier, Ionosphere, TEC, Earthquake.

*Sorumlu Yazar: skaratay@kastamonu.edu.tr 


\section{Giriş}

İyonosfer, atmosferin 50 ila $1000 \mathrm{~km}$ arasinda yer alan önemli bir katmanıdır. İyonosfer, aynı şekilde, plazma olarak anılan, yeterli miktarda yüklü parçacıkların bulunduğu üst iklim alanıdır. İyonosfer elektriksel olarak nötrdür; ancak güneş ışınları nüfuz ettiğinde, nötr parçacıklar iyonlaşarak iyonosferik plazmayı iletken hale getirir. Radyo dalgalarının iyonosferde çoğaldığ noktada yansıma, kırılma, dağılım, emilim, polarizasyon ve yayılım gerçekleşir. $\mathrm{Bu}$ nedenle iyonosfer katmanı, radyo telekomünikasyon, uydu haberleşme, HF (High Frequency: Yüksek Frekans) yayılımı, plazma fiziği ve uzay havası çalışmalarında önemli bir yere sahiptir (Fuller-Rowell vd., 2000).

İyonosferin en önemli parametresi, coğrafik konum, zaman, yükseklik, güneş hareketliliği ile jeomanyetik ve sismik hareketlilikle değişim gösteren ve metreküpte $10^{8}$ ile $10^{13}$ arasındaki değerlere sahip elektron yoğunluğudur. İyonosferin elektron yoğunluğu özellikle güneşteki ve buna bağlı olarak Yer'in manyetik alanındaki değişimlere bağlı olarak önemli değişimler sergiler. Güneş hareketliliğindeki ve buna bağlı olarak Yer'in manyetik alanındaki bu değişimler, bazı özel indislerle ölçülmektedir. İyonosfer için önemli bir diğer tanımlayıcı nicelik de, Toplam Elektron İçeriği'dir (TEI). 1 metrekare kesitli bir silindir boyunca toplam serbest elektron miktarı olarak da yorumlanan TEI'nin birimi TECU'dur. 1 TECU, metrekarede $10^{16}$ elektrona eşittir. TEİ değerleri incelenerek iyonosferdeki kısa ve uzun dönem değişimler yakından izlenebilir. İyonosfer araştırmaları ve TEİ kestirimi için, teorik ve deneysel modellerin yanında yer tabanlı ve uydu tabanlı çeşitli teknikler kullanılmaktadır. Son yıllarda, Yerküresel Konumlandırma Sistemi (YKS) alıcılarından oluşan sistemle, TEİ (YKS-TEİ) değerlendirmesinde ve iyonosferin değişkenliğini gözlemlemede uygun maliyetli bir imkân sağlar (Arikan vd., 2003; Arikan, vd., 2008; Sezen vd., 2013).

İyonosferin elektron yoğunluğu miktarı, 11-yıllık güneş döngüsüne, gece ve gündüze göre, dünyanın güneş etrafındaki ve ayın dünya etrafındaki aylık, mevsimlik ve yıllık hareketlerine bağlıdır. İyonosfer bu süreçlerde özellikle güneş hareketliliği ve buna bağlı olarak da jeomanyetik hareketliliğinin etkisinde, bazı aykırılıklar (anomaliler) sergiler. Özellikle güneş tutulmasının meydana geldiği dönemlerde, iyonosferin elektron yoğunluğunda azalmalar, tutulma zamanı boyunca iyonosferin E-Bölgesi'nde oluşan akımların meydana getirdiği manyetik alan şiddetinde azalmalar ve iyonosferin tüm katmanlarının kritik frekanslarında önemli değişimler meydana geldiği gözlenmiştir (Korte vd., 2001; Ozcan \& Aydogdu, 2004; Le vd., 2008). Son yıllarda yapılan çalışmalarda, sismik hareketliliğin de iyonosferde büyük ölçekli bozulmalar yarattığı ortaya konmuştur (Liu vd., 2000; Pulinets vd., 2003; Chen vd., 2004; Karatay vd., 2010). Güçlü sismik sarsıntılar sırasında, öncesinde ve sonrasında, iyonosferik parametrelerde, özellikle iyonosferin F2-Bölgesi kritik frekansında, parçacık sıcaklıklarında ve TEI'de önemli ölçüde aykırılıklar ve bozulmalar gözlenmiştir.

Literatürde, iyonosferik bozulmaların tespiti için tipik olarak, yer tabanlı çift frekanslı Küresel Navigasyon Uydu Sistemi (GNSS) alıcılarından kestirilen TEİ verilerine dayanan zamansal türev tabanlı yöntemler kullanılmıştır (Krankowski vd., 2006; Efendi \& Arikan, 2017; Karatay vd., 2017; Karatay, 2020). İstatistikte Naive Bayes sinıflandırıcıları, özellikler arasındaki güçlü (naif) bağımsızlık varsayımları ile Bayes Teoremi’nin uygulanmasina dayanan basit "olasılıksal sinıflandirıcılar" e-ISSN: 2148-2683 ailesidir. Bir Naive Bayes sınıflandırıcı, her özniteliğin birbirinden koşulsal bağımsız olduğu ve öğrenilmek istenen kavramın tüm bu özniteliklere koşulsal bağlı olduğu bir Bayes ağı olarak düşünülmektedir (Domingos \& Pazzani, 1997; Hand \& Yu, 2007). Bu çalışmada, 11 Ağustos 1999 güneş tutulması ve 17 Ağustos 1999 büyük Marmara Depremi dönemlerinde veri elde edilebilen iki YKS istasyonundan kestirilen TEI'nin değişkenliğini incelemek için, Naive Bayes sınıflayıcıları literatürde ilk defa bu bağlamda TEI veri seti üzerine uygulanmıştır. Çalışma kapsamında kullanılan Naive Bayes sınıflayıcılarına Bölüm 2'de; elde edilen bulgulara da Bölüm 3'te yer verilmiştir.

\section{Materyal ve Metot}

Herhangi bir YKS alıcısından, alıcı numarası u, toplam ölçüm sayısı $\mathrm{N}$ ve örnek numarası $\mathrm{n}$ olmak üzere, $\mathrm{d}$ günü için kestirilen TEİ değerleri, $\boldsymbol{x}_{\boldsymbol{u} ; \boldsymbol{d}}$ vektörüyle ifade edilir:

$x_{u ; d}=\left[x_{u ; d}(1) \ldots \ldots \ldots x_{u ; d}(n) \ldots \ldots \ldots x_{u ; d}(N)\right]^{T}$

Eşitlik (1)'de, $T$, transpoz operatörü ve $1 \leq n \leq N$ 'dir. $\mathrm{Bu}$ çalışmada, Naive Bayes Sınıflandırıcısı'nın uygulaması için kullanılan parametrelerden biri de IONOLAB-TEC olarak kestirilen TEİ değerleridir (IONOLAB).

Bayes Teoremi, sınıf değişkeni $y$ ve bağımlı özellik vektörünün $\boldsymbol{x}_{\boldsymbol{u} ; \boldsymbol{d}}(1)$ ile $\boldsymbol{x}_{\boldsymbol{u} ; \boldsymbol{d}}(N)$ örnekleri arasındaki aşağıdaki ilişkiyi belirtir (Scikit-Learn; Papoulis, 1984; Domingos \& Pazzani, 1997; Webb vd., 2005; Budak vd., 2016):

$P\left(y \backslash x_{u ; d}(1), \ldots, x_{u ; d}(N)\right)=\frac{P(y) P\left(x_{u ; d}(1), \ldots, x_{u ; d}(N) \backslash y\right)}{P\left(x_{u ; d}(1), \ldots, x_{u ; d}(N)\right)}$

Aşağıdaki eşitlikte verilen saf koşullu serbestlik varsayımı kabul edilirse (Scikit-Learn; Domingos \& Pazzani, 1997; Webb vd., 2005; Budak vd., 2016):

$$
\begin{aligned}
& P\left(\boldsymbol{x}_{\boldsymbol{u} ; \boldsymbol{d}}(n) \backslash y, \boldsymbol{x}_{\boldsymbol{u} ; \boldsymbol{d}}(1), \ldots, \boldsymbol{x}_{\boldsymbol{u} ; \boldsymbol{d}}(n-1), \boldsymbol{x}_{\boldsymbol{u} ; \boldsymbol{d}}(n+1), \ldots, \boldsymbol{x}_{\boldsymbol{u} ; \boldsymbol{d}}(N)\right) \\
& =P\left(y \backslash \boldsymbol{x}_{\boldsymbol{u} ; \boldsymbol{d}}(n)\right)
\end{aligned}
$$

Tüm n örnekleri için, Eşitlik (1), aşağıdaki gibi indirgenebilir (Scikit-Learn; Domingos \& Pazzani, 1997; Webb vd., 2005; Budak vd., 2016):

$$
P\left(y \backslash \boldsymbol{x}_{\boldsymbol{u} ; \boldsymbol{d}}(1), \ldots, \boldsymbol{x}_{\boldsymbol{u} ; \boldsymbol{d}}(N)\right)=\frac{P(y) \prod_{n=1}^{N} P\left(\boldsymbol{x}_{\boldsymbol{u} ; \boldsymbol{d}}(n) \backslash y\right)}{P\left(\boldsymbol{x}_{\boldsymbol{u} ; \boldsymbol{d}}(1), \ldots, \boldsymbol{x}_{\boldsymbol{u} ; \boldsymbol{d}}(N)\right)}
$$

Eşitlik (4)'te, $P\left(\boldsymbol{x}_{\boldsymbol{u} ; \boldsymbol{d}}(1), \ldots, \boldsymbol{x}_{\boldsymbol{u} ; \boldsymbol{d}}(N)\right)$ girdisi sabit olduğundan, aşağıda verilen sınıflandırma kuralı kullanılabilir (Scikit-Learn; Domingos \& Pazzani, 1997; Webb vd., 2005; Budak vd., 2016):

$$
P\left(y \backslash \boldsymbol{x}_{\boldsymbol{u} ; \boldsymbol{d}}(1), \ldots, \boldsymbol{x}_{\boldsymbol{u} ; \boldsymbol{d}}(N)\right) \propto P(y) \prod_{n=1}^{N} P\left(\boldsymbol{x}_{\boldsymbol{u} ; \boldsymbol{d}}(n) \backslash y\right)
$$

Böylelikle, Eşitlik (6) elde edilir (Scikit-Learn; Domingos \& Pazzani, 1997; Webb vd., 2005; Budak vd., 2016:

$\hat{y}=\arg \max _{y} P(y) \prod_{n=1}^{N} P\left(\boldsymbol{x}_{\boldsymbol{u} ; \boldsymbol{d}}(n) \backslash y\right)$

Eşitlik (5) ve (6) kullanılarak $P(y)$ ve $P\left(\boldsymbol{x}_{\boldsymbol{u} ; \boldsymbol{d}}(n) \backslash y\right)$ 'yi tahmin etmek için Maksimum A Sonsalı (Maksimum A Posteriori-MAP) tahmini kullanılabilir. Buradaki bir önceki, eğitim setindeki $y$ 
sınıfının göreceli frekansıdır. Saf Bayes sınıflandırıcıları, gerekli parametreleri tahmin etmek için az miktarda eğitim verisine ihtiyaç duyarlar (Scikit-Learn; Domingos \& Pazzani, 1997; Webb vd., 2005; Budak vd., 2016).

\subsection{Gaussian Naive Bayes Sinıflayıcısı}

Sürekli verilerle çalışırken, sıklıkla kabul edilen bir varsayım, her sınıfla ilişkili sürekli değerlerin normal (veya Gauss) bir dağılıma göre dağıtıldığıdır. Gaussian Naive Bayes, sınıflandırma için Gauss Naive Bayes algoritmasını uygular. Özelliklerin olasılığının Gauss olduğu varsayılır (Papoulis, 1984; Domingos \& Pazzani, 1997; Webb vd., 2005; Budak vd., 2016; Witten vd., 2016):

$P\left(\boldsymbol{x}_{\boldsymbol{u} ; \boldsymbol{d}}(n) \backslash y\right)=\frac{1}{\sqrt{2 \pi \sigma_{y}^{2}}} \exp \left(-\frac{\left(\boldsymbol{x}_{\boldsymbol{u} ; \boldsymbol{d}}(n)-\mu_{y}\right)^{2}}{2 \sigma_{y}^{2}}\right)$

Yukarıdaki bağıntıda $\sigma_{y}$ ve $\mu_{y}$ sırasıyla, sınıf değişkeni $y$ 'nin Bessel düzeltilmiş değişinti (varyans) ve ortalama değerini ifade etmektedir. Gauss Naive Bayes, her biri bir Gauss (normal) dağılıma uygun olarak sürekli değerli özellikleri ve modelleri destekler (Papoulis, 1984; Domingos \& Pazzani, 1997; Webb vd., 2005; Budak vd., 2016; Witten vd., 2016).

$\mathrm{Bu}$ çalışmada da, tam güneş tutulması ve depremine iyonosferin olası tepkilerinin istatistiksel analizi ve YKS istasyonlarından elde edilen TEI'nin değişkenliğini incelemek için, iyonosferin jeomanyetik açıdan bozulmalı ve sakin durumları da göz önüne alınarak, Gaussian Naive Bayes sınıflayıcısı literatürde ilk defa bu bağlamda TEİ veri seti üzerinde uygulanmıştır. Elde edilen sonuçlara Bölüm 3 'te yer verilmiştir.

\section{Araştırma Sonuçları ve Tartışma}

$\mathrm{Bu}$ çalışmada, veri kaynağı olarak çift frekanslı YKS alıcılarından IONOLAB-TEC olarak kestirilen TEİ değerleri kullanılmıştır. Düzenlenmiş Kestirim (Regularized-Estimation: Reg-Est) algoritmasına dayanan IONOLAB-TEC, çift frekanslı YKS alıcılarından yerel zenit yönünde tek bir istasyon üzerinden YKS-TEİ kestirimi sağlayan, literatürdeki en sağlam, güvenilir ve doğru algoritmalardan biridir (Arikan vd., 2003; Arikan vd., 2004).

Bu çalışmada, ilk olarak, Bölüm 2'de anlatılan Gaussian Naive Bayes sınıflayıcısı, bazı bozulmaların olduğu günlerde Şekil 1'de konumları gösterilmiş YKS istasyonlarından kestirilen IONOLAB-TEC değerleri ile bazı güneş ve jeomanyetik indisleri içeren veri setine uygulanmıştır. Olaylar, 11 Ağustos 1999 güneş tutulmasını ve 17 Ağustos 1999 Marmara Depremi'ni, çeşitli güneş, jeomanyetik ve sismik hareketliliğin de olduğu yirmi günlük bir periyodu içermektedir. Marmara Depremi 17 Ağustos 1999 tarihinde YZ 03.02'de (GS 00:00:02) Gölcük, Kocaeli'nde meydana geldi. Depremin Richter ölçeğine göre büyüklüğü $\mathrm{Mw}$ 7.5 olarak kaydedildi. Depremin merkez üssü $40.70^{\circ} \mathrm{K}$ ve $29.91^{\circ}$ D coğrafi koordinatlarında yer almaktadır ve Şekil 1'de, kırmızı yıldız ve DM ile gösterilmiştir (USGS). Depremin merkez üssünü çevreleyen mevcut IGS (International GNSS Service) istasyonlarından sadece ankr $\left(39.69^{\circ} \mathrm{K}, 32.75^{\circ} \mathrm{D}\right)$ Ankara, Türkiye ve tubi $\left(40.59^{\circ} \mathrm{K}, 29.45^{\circ} \mathrm{D}\right)$ Gebze, Türkiye'den veri sağlanabilmiştir. Bu istasyonların konumu Şekil 1'de verilmiştir.

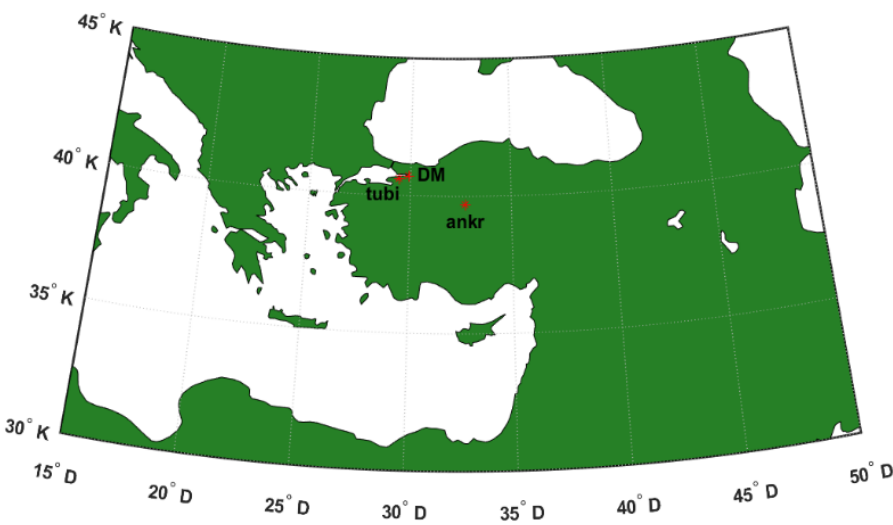

Şekil 1. Çalışma kapsamında kullanılan IGS istasyonları ve Deprem Merkezi (DM).

Jeomanyetik Kp ve Ap indisleri ve güneş indisleri GLS ve F10.7, Space Weather Prediction Center'dan sağlanmıştır (NOAA). Yine, jeomanyetik indisler AE ve Dst de World Data Center for Geomagnetism'den elde edilmiştir (World Data Center for Geomagnetism). Kp, Ap, AE, Dst, GLS ve F10.7 indislerinin yirmi günlük değişimi Şekil 2'de verilmiştir.
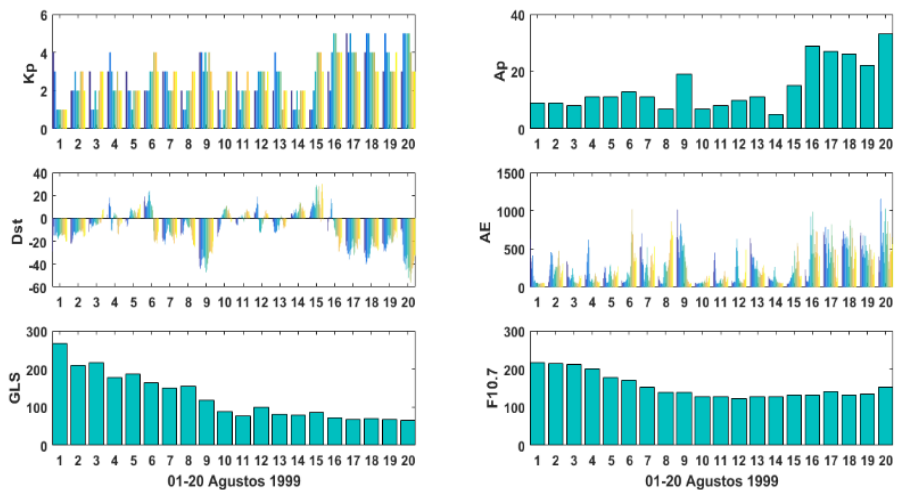

Şekil 2. 01 ila 20 Ağustos 1999 tarihleri arasındaki Ap, Kp, Dst, AE, GLS ve F10.7 indislerinin değişimi (NOAA; World Data Center for Geomagnetism).

Şekil 3'te 11 ve 17 Ağustos tarihlerinde ankr ve tubi istasyonları için IONOLAB-TEC değerleri verilmiştir. Tam güneş tutulmasının gözlendiği ve depremin meydana geldiği saatler, Greenwich Saati'ne (GS) göre kırmızı oklarla gösterilmiştir. Tam güneş tutulmasının hemen ardından, her iki istasyon için IONOLAB-TEC değerlerinde ani bir azalma gözlenmektedir. Her iki olayda da IONOLAB-TEC'in Türkiye için dinamik seviyesinin çok da değişmediği görülmektedir.

$\mathrm{Bu}$ çalışmada güneş tutulmasının ve sismik hareketliliğin iyonosferde meydana getirdiği etkileri incelemek için, Naive Bayes sınıflayıcılarından Gaussian Naive Bayes sınıflayıcısı, 01 ila 20 Ağustos tarihleri için IGS ankr ve tubi istasyonlarından kestirilen IONOLAB-TEC verilerine uygulanmıştır. Özellikle tubi istasyonu, 11 Ağustos 1999'daki depremin merkezine oldukça yakındır. Diğer kontrol istasyonu olarak seçilen ankr istasyonunun da deprem merkezine uzaklığı 300 km'den fazladır. Her iki istasyon için yirmi günlük veride, iyonosferin sakin olduğu ve hiçbir olayın gerçekleşmediği örnek sayısı 11.393'tür. Güneş hareketliliğinin gözlendiği örnek sayısı 75; sismik hareketliliğin gözlendiği örnek sayısı da 52'dir. 

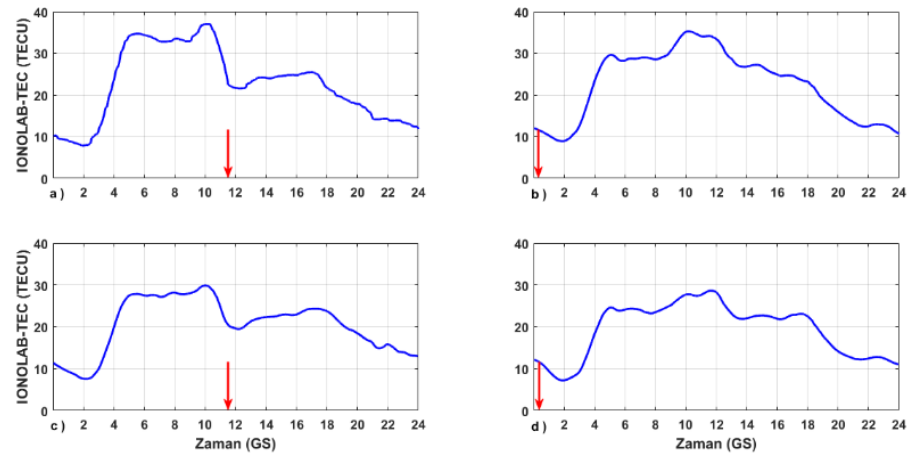

Şekil 3. 11 Ağustos 1999 tarihinde a) ankr, c) tubi ve 17 Ağustos 1999 tarihinde b) ankr, d) tubi istasyonları için IONOLAB-TEC değerleri (IONOLAB).

Şekil 4'te, sırasıyla tubi ve ankr istasyonu için istatistiksel analiz sonuçları verilmiştir. Elde edilen tüm bulgularda ve Şekil 4'te, IONOLAB-TEC değerleri "tec", GLS değerleri "sun" ve F10.7 değerleri de "solar" olarak isimlendirilmiştir. Şekle bakıldığında, deprem merkezinden uzaklaştıkça ortalama değer, standart sapma, minimum, çeyrekler ve maksimum değerlerinin arttığı gözlenmektedir.

\begin{tabular}{|c|c|c|c|c|c|c|c|}
\hline Index & tec & ap & $\mathrm{kp}$ & sun & solar & ae & dst \\
\hline count & 11520 & 11520 & 11520 & 11520 & 11520 & 11520 & 11520 \\
\hline mean & 22.22 & 14.55 & 2.73 & 153.5 & 124.8 & 279.8 & -9.44 \\
\hline std & 7.18 & 8.18 & 1.12 & 31.53 & 59.75 & 232.96 & 15.68 \\
\hline $\min$ & 6.41 & 5 & 0 & 123 & 65 & 39 & -56 \\
\hline $25 \%$ & 16.84 & 8.75 & 2 & 130.25 & 74.75 & 81 & -20 \\
\hline $50 \%$ & 22.92 & 11 & 3 & 138 & 94.5 & 203 & -9 \\
\hline $75 \%$ & 27.21 & 19.75 & 3 & 171.75 & 167.25 & 437.25 & 3 \\
\hline $\max$ & 41.33 & 33 & 5 & 216 & 267 & 1155 & 30 \\
\hline
\end{tabular}

a)

\begin{tabular}{|c|c|c|c|c|c|c|c|}
\hline Index & tec & ap & $\mathrm{kp}$ & sun & solar & ae & dst \\
\hline count & 11520 & 11520 & 11520 & 11520 & 11520 & 11520 & 11520 \\
\hline mean & 25.83 & 14.55 & 2.73 & 153.5 & 124.8 & 279.8 & -9.44 \\
\hline std & 9.55 & 8.18 & 1.12 & 31.53 & 59.75 & 232.96 & 15.68 \\
\hline $\min$ & 7.25 & 5 & 0 & 123 & 65 & 39 & -56 \\
\hline $25 \%$ & 17.9 & 8.75 & 2 & 130.25 & 74.75 & 81 & -20 \\
\hline $50 \%$ & 26.09 & 11 & 3 & 138 & 94.5 & 203 & -9 \\
\hline $75 \%$ & 32.52 & 19.75 & 3 & 171.75 & 167.25 & 437.25 & 3 \\
\hline $\max$ & 51.43 & 33 & 5 & 216 & 267 & 1155 & 30 \\
\hline
\end{tabular}

b)

Şekil 4. a) tubi ve b) ankr istasyoları için kullanılan toplam veri üzerinden her bir parametre için sırasıyla ortalama değer, standart sapma, minimum, çeyrekler ve maksimum değerleri.

Şekil 5'te, tubi istasyonlarının IONOLAB-TEC değerlerinin normalize edilmiş kutucuklara göre kestirilmiş frekansları verilmiştir. Şekle bakıldığında tubi istasyonu için en büyük frekansın 25 TECU civarında; ankr istasyonu için de en büyük frekansın 30 TECU civarında kümelendiği görülmektedir. Deprem merkezine yaklaştıkça TEİ değerleri azalmıştır. Ortalama değer tubi istasyonu için $\mu=22.22$ olarak; ankr istasyonu için de $\mu=25.83$ olarak elde edilmiştir. Deprem merkezinden uzaklaştıkça ortalama değerin arttığı gözlenmektedir.

Şekil 6'da, tubi ve ankr istasyonları için, veri setinde kullanılan yedi parametrenin, birbirleriyle ilintilerini gösteren Öznitelik İlinti Isı Haritası verilmiştir. Şekil 6'ya bakıldığında, tubi istasyonu için en yüksek ilintinin 0.9 değeriyle GLS ile F10.7 arasında olduğu görülmektedir. İkinci en yüksek ilinti ise 0.71 değeriyle $\mathrm{AE}$ ve $\mathrm{Kp}$ indisleri arasında olduğu gözlenmektedir. IONOLAB-TEC ile en yüksek ve pozitif ilintiye de 0.34 oranıyla F10.7 indisinin sahip olduğu görülmektedir. Birbirlerinden türeyen Ap ve Kp indileri arasındaki ilintinin de 0.69 olduğu, görülmektedir. Yine Şekil 6'ya bakıldığında, IONOLAB-TEC ile en yüksek ve pozitif ilintinin ankr istasyonu için 0.30 oranıyla F10.7 indisinin sahip olduğu görülmektedir. Bu oranın, tubi istasyonuna göre daha küçük olması, ankr istasyonunun coğrafi konumuna (enlem farkı) göre farklılık göstermesiyle açıklanabilir.
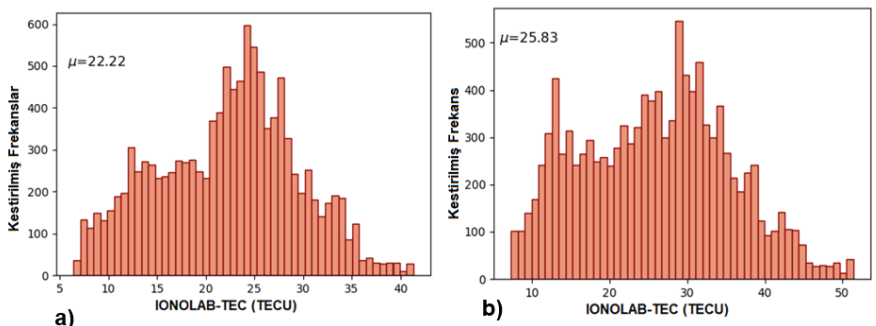

Şekil 5. a) tubi ve b) ankr istasyonlarına ait IONOLAB-TEC için kestirilmiş frekanslar.
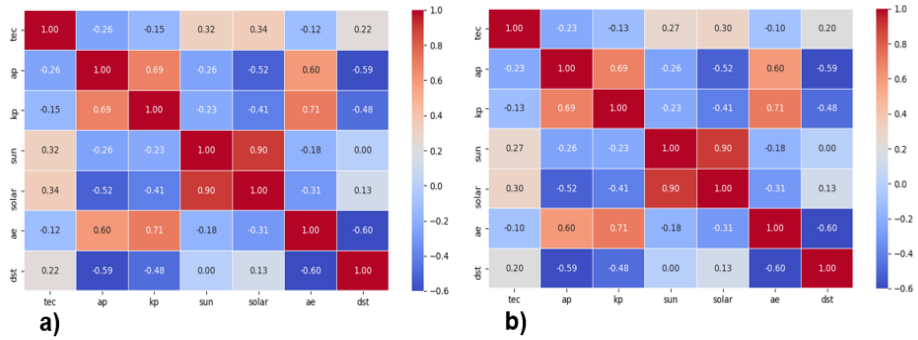

Şekil 6. a) tubi ve b) ankr istasyonları için parametreler arası Öznitelik İlinti Is1 Haritas1.

Merkez istasyon tubi için kullanılan normal örnek sayısı 3279, deprem örnek sayısı 126 ve güneş örnek sayısı 51'dir. Merkez istasyon tubi için Gaussian Naive Bayes sınıflayıcısı, bu üç olayda kullanılan örnek sayılarından 3279 normal örneğin 3279'unu; 126 deprem örneğinin 19'unu ve 51 güneş örneğinin 24'ünü doğru tahmin etmiştir. Bu da sirasıyla, \%100, \%15 ve \%47 tahmin oranlarına karşılık gelmektedir. Gaussian Naive Bayes sınıflayıcısı için toplam tahmin oranı \%96.12 olarak elde edilmiştir.

Kontrol istasyonu ankr için normal örnek sayısı 3282, deprem örnek sayısı 107 ve güneş örnek sayısı 24'tür. Gaussian Naive Bayes sınıflayıcısı, bu üç olayda kullanılan örnek sayılarından 3282 normal örneğin 3282'sini tahmin ederek \%100 sonuç vermiştir. Yine Gaussian Naive Bayes sınıflayıcısı 126 deprem örneğinin 19'unu tahmin ederek \%15 sonuç vermiştir. Son olarak da Gaussian Naive Bayes sınıflayıcısı, 48 güneş örneğinin 24’ünü doğru tahmin ederek \%50 doğru sonuç vermiştir. Merkez istasyon tubi için elde edilen sonuçlarla karşılaştırıldığında, IONOLABTEC üzerinden normal ve deprem tahminlerinin değişmediği, sadece \%0.03 kadar tahmin doğruluğunun arttığı gözlenmiştir. Bu durum yine, iki istasyon arasındaki coğrafik konum farklılığıyla açıklanabilir. Her üç durum için Gaussian Naive Bayes sınıflayıcısı kullanılarak ankr istasyonu için elde edilen toplam tahmin oranı \%96.20'dir. Toplam tahmin doğruluk oranında da ankr istasyonu için elde edilen oran $\% 0.08$ daha büyük olarak elde edilmiştir. Önce tubi istasyonu, sonra da ankr istasyonu için elde 
edilen Model Performans Metrikleri, Ekler bölümünde verilmiştir.

Çalışmanın son kısmında, merkez istasyon tubi ve kontrol istayonu ankr'nin birleşik istatistiksel analizi yapılmıştır. Şekil 7'de, tubi ve ankr istasyonun deprem, güneş ve normal durumlarındaki birleşik istatistikleri verilmiştir. Şekil 7 incelendiğinde, IONOLAB-TEC için en küçük ortalama değerin deprem durumunda ortaya çıktığı görülmektedir. Güneş ve normal durumda elde edilen ortalama değerler birbirine çok yakındır. Deprem durumunda ortalama değer neredeyse yarıya yarıya azalmıştır. Buna karşın standart sapma, güneş durumunda 1.5'e, deprem durumunda da 4.87'ye düşmüştür. iyonosferde bir bozulma meydana geldiğinde, standart sapma azalmıştır. Normal durumda daha düşük olan minimum değer, deprem durumunda biraz artmış, güneş durumunda ise oldukça artmıştır. Güneş tutulması ve deprem meydana geldiğinde, IONOLAB-TEC'in minimum değerlerinde artışlar gözlenmiştir. Normal dönemde maksimum değer 51.43 TECU iken, deprem ve güneş durumunda maksimum değer yarı yarıya azalarak 24.87 TECU değerini almıştır.

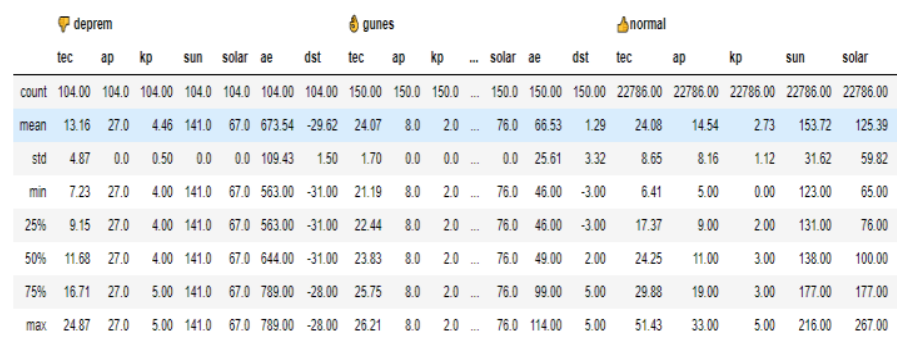

Şekil 7 ankr ve tubi istasyonları için kullanılan toplam veri üzerinden her bir parametre için sırasıyla ortalama değer, standart sapma, minimum, çeyrekler ve maksimum değerleri.

Merkez istasyon tubi ile kontrol istasyonu ankr'nin birleşik frekans analizi ile birleşik kestirilmiş frekansları elde edilmiştir. İstasyonların birleşik frekanslarının 25 TECU civarında kümelendiği gözlenmiştir. Öznitelik Isı haritasında da, IONOLAB-TEC'in en büyük ilintiye F10.7 ile 0.30 oranında sahip olduğu gözlenmiştir. Birleşik analizde kullanılan normal durum örnek sayıs1 22.786, güneş durumu örnek sayısı 150 ve deprem durumu örnek sayısı da 104'tür.

\section{Sonuç}

$\mathrm{Bu}$ çalışmada, güneş ve sismik hareketliliğin iyonosferde meydana getirdiği bozulma ve düzensizlikler, 11 Ağustos 1999 güneş tutulması ve 17 Ağustos 1999 Marmara Depremi periyodunca IGS ağı içinde yer alan iki istasyondan kestirilen IONOLAB-TEC verileri kullanılarak incelenmiştir. Çalışma kapsaminda, merkez istasyon konumunda tubi ve kontrol istasyonu konumunda ankr istasyonlarından elde edilen IONOLAB-TEC verilerine ve dört jeomanyetik ile iki güneş indisi verilerine Gaussian Naive Bayes sınıflayıcısı uygulanarak, iyonosferin yirmi günlük zaman aralığında istatistiksel analizi yapılmıştır. Elde edilen bulgularda, istasyonların deprem merkezine uzaklığı arttıkça, ortalama değer, standart sapma, minimum, çeyrekler ve maksimum değerlerin de arttı̆̆ gözlenmiştir. Deprem merkezine daha yakın istasyonun IONOLAB-TEC değerlerinde deprem döneminde 5 TECU kadar bir azalma meydana geldiği, dolaysıyla, yakın istasyonun IONOLAB-TEC değerlerinin, uzak istasyona göre daha az bir frekansta kümelendiği gözlenmiştir.
Çalışma kapsamında seçilen yedi parametrenin çapraz ilinti analizinde, TEİ ile ilintisi en yüksek olan parametrenin, güneş akı indisi F10.7 olduğu tespit edilmiştir. Gaussian Naive Bayes sınıflayıcısının uygulanmasında, deprem, güneş ve hiçbir olayın gözlenmediği ve iyonosferin sakin kabul edildiği normal durumları olmak üzere üç durum kabul edilmiştir. Sınıflayıcının, deprem olarak kabul edilen ihtimali, her iki istasyon için de eşit ve \%15 olarak tahmin edebildiği gözlenmiştir. Aynı sınıflaycının, güneş hareketliliği ihtimalini de her iki istasyon için benzer oranlarda tahmin edebildiği gözlenmiştir. İki istasyonun birleşik istatistiksel analizinde, IONOLAB-TEC için en küçük ortalama değerin deprem durumunda ortaya çıktığı; güneş ve normal durumda elde edilen ortalama değerler birbirine çok yakın olduğu gözlenmiştir. Minimum değerin, deprem durumunda biraz; güneş durumunda ise oldukça arttığ tespit edilmiştir. Maksimum değerin ise deprem ve güneş durumunda yarı yarıya azaldığı gözlenmiştir.

Bu çalışmada, Gaussian Naive Bayes sınıflayıcısı, literatürde ilk defa YKS-TEİ verilerine uygulanmış ve bu kapsamda ilk defa kullanılmıştır. Gelecek çalışmalar, sadece YKS-TEI verileri kullanılmak, daha fazla istasyon ağı üzerinden ve sismik hareketliliğin bozduğu verilerin sayısı geniş tutulmak, çalışılan olay (deprem) sayısı arttırılmak suretiyle yapılacak ve başka öğrenme ve sinyal işleme teknikleri de denenecektir.

\section{Teşekkür}

$\mathrm{Bu}$ çalışmada, IONOLAB-TEC'in hesaplanmasında kullanılan GIM-TEC, Satellite DCB ve efemeris verileri, ftp:/cddis.gsfc.nasa.gov/pub/gps/products/ionex adresindeki IGS Analysis Center of Jet Propulsion Laboratory (JPL)'den sağlanmıştır. Yazarlar, makaleyi geliştirmede yazarlar için çok yararlı ve yapıcı olan yorumları ve katkıları için anonim hakemlere teşekkür eder. Yazarlar son olarak, Prof. Dr. Feza Arıkan ve IONOLAB grubuna IONOLAB-BIAS ve IONOLABTEC Algoritması üzerindeki üstün emeklerinden dolayı teşekkür eder.

\section{Ekler}

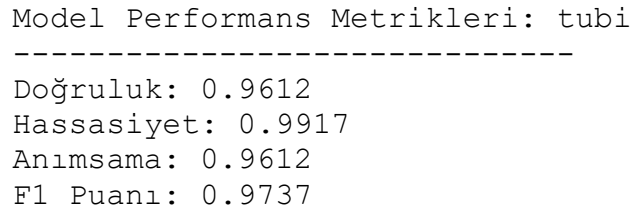

Model Sınıflama Raporu:

$\begin{array}{lcccc} & \text { hassasiyet } & \text { anımsama } & \text { f1-puanı } & \text { destek } \\ \text { normal } & 1.00 & 0.96 & 0.98 & 3413 \\ \text { deprem } & 0.15 & 1.00 & 0.26 & 19 \\ \text { güneş } & 0.47 & 1.00 & 0.64 & 24 \\ \text { doğruluk } & & & & \\ \text { makro ort } & 0.54 & 0.99 & 0.96 & 3456 \\ \text { ağırlık ort } & 0.99 & 0.96 & 0.97 & 3456\end{array}$

Tahmin Karışıklık Matrisi:

$$
\begin{aligned}
& \begin{array}{r}
-------------------------- \\
\text { Tahmin edilen: }
\end{array} \\
& \text { normal deprem güneş } \\
& \begin{array}{lrrr}
\text { Gerçek: normal } & 3279 & 107 & 27
\end{array}
\end{aligned}
$$


deprem

güneş

$0 \quad 19$

0

24

Model Performans Metrikleri: ankr

$---------$

Doğruluk: 0.9621

Hassasiyet: 0.9919

Anımsama: 0.9621

F1 Puanı: 0.9743

Model Sınıflama Raporu:

\begin{tabular}{|c|c|c|c|c|}
\hline \multicolumn{2}{|c|}{ hassasiyet } & anımsama & f1-puanı & destek \\
\hline normal & 1.00 & 0.96 & 0.98 & 3413 \\
\hline deprem & 0.15 & 1.00 & 0.26 & 19 \\
\hline güneş & 0.5 & 1.00 & 0.67 & 24 \\
\hline doğruluk & & 0.96 & 3456 & \\
\hline makro ort & 0.55 & 0.99 & 0.64 & 3456 \\
\hline ağırlık ort & 0.99 & 0.96 & 0.97 & 3456 \\
\hline
\end{tabular}

Tahmin Karışıklık Matrisi:

\begin{tabular}{crrr} 
& \multicolumn{4}{c}{ Tahmin edilen: } \\
Gerçek: normal & normal deprem güneş & gün \\
deprem & 3282 & 107 & 24 \\
güneş & 0 & 19 & 0 \\
& 0 & 0 & 24
\end{tabular}

\section{Kaynakça}

Arikan, F., Erol, C., \& Arikan, O. (2003). Regularized estimation of vertical total electron content from Global Positioning System data. Space Physics, 108(A12), 1-12. doi:10.1029/2002JA009605

Arikan, F., Erol, C., \& Arikan, O. (2004). Regularized estimation of vertical total electron content from GPS data for a desired time period. Radio Science, 39(6), 1-10. doi:10.1029/2004RS003061

Arikan, F., Nayir, H., Sezen, U., \& Arikan, O. (2008). Estimation of single station interfrequency receiver bias using GPS-TEC. Radio Science, 43(4), 1-13. doi:10.1029/2007RS003785

Budak, C., Turk, M., \& Toprak, A. (2016). Removal of impulse noise in digital images with naive Bayes classifier method. Turkish Journal of Electrical Engineering \& Computer Sciences, 24(4), 2717 - 2729. doi:10.3906/elk-1401-57

Chen, Y., Liu, J., Tsai, Y., \& Chen, C. (2004). Statistical Tests for Pre-earthquake Ionospheric Anomaly. Terrestrial Atmospheric and Oceanic Sciences, 15(3), 385-396. doi:10.3319/TAO.2004.15.3.385(EP)

Domingos, P., \& Pazzani, M. (1997). Beyond independence: Conditions for the optimality of the simple Bayesian classifier. Machine Learning, 29, 103-130.

Efendi, E., \& Arikan, F. (2017). A fast algorithm for automatic detection of ionospheric disturbances: DROT. Advances in Space Research, 59(12), 2923-2933. doi:10.1016/j.asr.2017.03.018

Fuller-Rowell, T., Codrescu, M., \& Wilkinson, P. (2000). Quantitative modeling of the ionospheric response to geomagnetic activity. Annales Geophysicae, 18, 766-781. doi:10.1007/s00585-000-0766-7

Hand, D., \& Yu, K. (2007). Idiot's Bayes: Not So Stupid after All? International Statistical Review, 69(3), 385 - 398. doi:10.1111/j.1751-5823.2001.tb00465.x
IONOLAB.IONOLAB: www.ionolab.org adresinden alınd

Karatay, S. (2020). Estimation of frequency and duration of ionospheric disturbances over Turkey with IONOLAB-FFT algori. Journal of Geodesy, 94(89), 1-24. doi:10.1007/s00190-020-01416-1

Karatay, S., Arikan, F., \& Arikan, O. (2010). Investigation of total electron content variability due to seismic and geomagnetic disturbances in the ionosphere. Radio Science, 45(5), 1-12. doi:10.1029/2009RS004313

Karatay, S., Cinar, A., \& Arikan, F. (2017). Ionospheric responses during equinox and solstice periods over Turkey. Advances in Space Research, 60(9), 1958-1967. doi:10.1016/j.asr.2017.07.038

Korte, M., Lühr, H., Förster, M., Haak, V., \& Bencze, P. (2001). Did the solar eclipse of August 11, 1999, show a geomagnetic effect? Journal of Geophysical Research, 106(A9), 1856318575. doi:10.1029/2001JA900006

Krankowski, A. 1., Shagimuratov, I., Baran, L., Ephishov, I., \& Tepenitzyna, N. (2006). The occurrence of polar cap patches in TEC fluctuations detected using GPS measurements in southern hemisphere. Advances in Space Research, 38(11), 2601-2609. doi:10.1016/j.asr.2005.12.006

Le, H., Liu, L., Yue, X., \& Wan, W. (2008). The ionospheric responses to the 11 August 1999 solar eclipse: observations and modeling. Annales Geophysicae, 26(1), 107-116. doi:10.5194/angeo-26-107-2008

Liu, J., Chen, Y., Pulinets, S., Tsai, Y., \& Chuo, Y. (2000). Seismoionospheric signatures prior to $\mathrm{M} \geq 6.0$ Taiwan earthquakes. Geophysical Research Letters, 27(16), 3113-3116. doi:10.1029/2000GL011395

NOAA. NOAA: ftp://ftp.swpc.noaa.gov/pub/indices/old_indices/ adresinden alınd 1

Ozcan, O., \& Aydogdu, M. (2004). Possible effects of the total solar eclipse of August 11, 1999 on the geomagnetic field variations over Elaziğ-Turkey. Journal of Atmospheric and Solar-Terrestrial Physics, 66(11), 997-1000. doi:10.1016/j.jastp.2004.03.009

Papoulis, A. (1984). Probability, Random Variables, and Stochastic Processes. New York, USA: McGraw-Hill.

Pulinets, S., Legen'ka, A., Gaivoronskaya, T., \& Depue, V. (2003). Main phenomenological features of ionospheric precursors of strong earthquakes. Journal of Atmospheric and SolarTerrestrial Physics, 65(16-18), 1337-1347. doi:10.1016/j.jastp.2003.07.011

Scikit-Learn. Scikit-Learn https://scikitlearn.org/stable/modules/naive_bayes.html\#out-of-corenaive-bayes-model-fitting adresinden alınd1

Sezen, U., Arikan, F., Arikan, O., Ugurlu, O., \& Sadeghimorad, A. (2013). Online, automatic, near-real time estimation of GPS-TEC: IONOLAB-TEC. Space Weather, 11(5), $297-$ 305. doi: $10.1002 /$ swe. 20054

USGS.USGS: $\quad$ https://earthquake.usgs.gov/earthquakes adresinden alınd 1

Webb, G., Boughton, J., \& Wang, Z. (2005). Not So Naive Bayes: Aggregating One-Dependence Estimators. Machine Learning, 58, 5-24. doi:doi.org/10.1007/s10994-005-4258-6

Witten, I., Frank, E., Hall, M., \& Pal, C. (2016). Data Mining: Practical Machine Learning Tools and Techniques. Burlington, Massachusetts: Morgan Kaufmann.

World Data Center for Geomagnetism. World Data Center for Geomagnetism: http://wdc.kugi.kyoto-u.ac.jp/index.html adresinden alınd 1 